\title{
Hyperprolinemia type 2
}

INSERM

\section{Source}

INSERM. (1999). Orphanet: an online rare disease and orphan drug data base.

Hyperprolinemia type 2. ORPHA:79101

Hyperprolinemia type 2 is an autosomal recessive proline metabolism disorder due to pyroline-5-carboxylate dehydrogenase deficiency. The condition is often benign but clinical signs may include seizures, intellectual deficit and mild developmental delay. 